\title{
REDUÇÃO DE DANOS: UMA ESTRATÉGIA DE TRATAMENTO OU INCENTIVO AO ALCOOLISMO?
}

DOI: $10.22289 / 2446-922 X . V 2 S 1 A 11$

\author{
Luciana Alves Dornela ${ }^{1}$ \\ Juliana Amorim Pacheco de Oliveira²
}

\section{INTRODUÇÃO}

O uso abusivo do álcool é um fenômeno da modernidade e um problema de saúde pública mundial(1). No Brasil, o alcoolismo é a terceira doença mais prevalente, superada apenas pelas doenças cardiovasculares e câncer ${ }^{(2)}$, além de responder por cerca de $10 \%$ das mortes no país ${ }^{(3)}$. A estratégia de Redução de Danos (RD) busca alternativas frente à gravidade deste problema, cujo objetivo é aumentar a qualidade de vida dos usuários de álcool, alicerçada fortemente no vínculo e empatia entre profissionais e usuários ${ }^{(4)}$, sem estabelecer a abstinência total como meta principal(5). É uma estratégia que incentiva ao protagonismo e a autonomia do usuário, resgata sua condição de sujeito na perspectiva dos direitos humanos. Além do mais, não coloca a abstinência como o único objetivo a ser almejado, constrói-se junto ao usuário possibilidades para melhorar a sua qualidade de vida ${ }^{(5)}$.

\section{MÉTODOS}

O presente estudo foi realizado por meio de revisão da literatura, sendo um texto descritivo, qualitativo. Foram utilizados materiais como livros, artigos e manuais, buscados no banco e dados SCIELO, BIREME, PEPSIC, e também sites das instituições de ensino superior e sites do Ministério da Saúde. O idioma foi o português e as publicações preferencialmente do ano de 2005 a 2015. Levantados a partir do cruzamento das palavras-chave: Alcoolismo. Redução de danos. Saúde Pública.

\section{RESULTADOS E DISCUSSÃO:}

A RD é uma política que surge enquanto estratégia de saúde pública que visa controlar possíveis consequências negativas associadas ao consumo de drogas lícitas e

\footnotetext{
${ }^{1}$ Graduanda em Psicologia pela Faculdade Patos de Minas (FPM).

${ }^{2}$ Mestre em Promoção de Saúde pela Universidade de Franca (UNIFRAN). Docente do Departamento de Graduação em Psicologia da Faculdade Patos de Minas (FPM). E-mail de contato: juamorimpacheco@hotmail.com.
} 

ilícitas, sem necessariamente interferir na oferta, ou seja, respeita a liberdade do usuário de escolher usar ou não, buscando a inclusão social e a cidadania do usuário(6).A RD não se restringe a um único modelo como a troca de seringas, destaca-se pelo olhar além do sintoma, que inclui o profissional não deixar-se guiar por uma fórmula pronta da construção de um suposto saber sobre o usuário ${ }^{(7)}$. Estudos mostram como pode ser ampla a RD e seria um equívoco achar que o papel do profissional é somente tratar o abuso de droga, o que o direciona para a abstinência total ${ }^{(7)}$. Quando se coloca na posição de um molde do saber constituído, o profissional não expande sua autoconsciência, não se permite avaliar a prática cotidiana do usuário, deixando de interrogá-la em sua própria existência ${ }^{(7)}$. Além de um saber do profissional são necessárias outas estratégias para compreender o usuário na sua subjetividade $^{(8)}$.

\section{CONSIDERAÇÕES}

Com este trabalho concluiu-se que a RD é de suma importância nos dias atuais, pois contraria o modelo manicomial, cuja finalidade não era tratamento e sim, a higienização social. As pessoas eram abandonadas nos manicômios pelos seus familiares, estratégia usada quando não se sabe o que fazer com o que não se consegue compreender. A estratégia é eficaz, pois possibilita construir vínculos, uma melhor qualidade de vida para os usuários e seus familiares, que podem aprender a ajudar seu ente querido sem necessariamente preterilo. Estudos mostram como pode ser ampla a RD a partir de acolhimentos diferenciados, construções a partir da fala dos usuários, o resgate da noção de integralidade. E quando essas questões são esquecidas, se torna um equívoco achar que o papel do profissional é somente tratar o uso e o abuso de droga, o que apenas direciona para a abstinência total. É possível perceber que ainda existem vários desafios em torno da eficácia e da falta de clareza relacionada a esta estratégia, o que dificulta a sua prática por profissionais na rede de saúde pública. Cabe a eles compreenderem que ofertar cuidado na perspectiva da RD não é estimular o uso de drogas. Assumir o compromisso com a estratégia não facilita o trabalho, pelo contrário, apenas o torna mais potente.

\section{REFERÊNCIAS}

1. Políticas Sobre Drogas no Brasil: a Estratégia de Redução de Danos. PSICOLOGIA: CIÊNCIA E PROFISSÃO, 2013, 33 (3), 580-595. 
2. Organização Mundial da Saúde. Relatório sobre a Saúde no Mundo 2001 - Saúde Mental: Nova Concepção, Nova Esperança. OMS: Genebra; 2001.

3.Ministério da Saúde. Secretaria Executiva. Secretaria de Atenção a Saúde.

Coordenação Nacional DST/AIDS. A Política do Ministério da Saúde para Atenção Integral a Usuários de Álcool e Outras Drogas. Ministério da Saúde, Secretaria Executiva, Secretaria de Atenção a Saúde, Coordenação Nacional-DST/AIDS.1a ed. Brasília: Ministério da Saúde; 2003.

4.BRASIL, MINISTÉRIO DA SAÚDE. Cadernos de Atenção Básica n³4-Saúde Mental. Brasília, Editora MS, $1^{\circ}$ ed.2013.

5.Conselho Federal de Psicologia Referências Técnicas para a Atuação de Psicólogas/os em Políticas Públicas de Álcool e Outras Drogas/ Conselho Federal de Psicologia. -Brasília: CFP; 2013.IAS

6.Brasil. Portaria $n^{\circ} 2.197$, de 14 de outubro de 2004.Redefine e amplia a atenção integral para usuários de álcool e outras drogas, no âmbito do Sistema Único de Saúde -SUS, e dá outras providências. Brasília; 2004.

7.Conselho Federal de Psicologia Subjetividade do consumo de álcool e outras drogas e as políticas públicas brasileiras / Conselho Federal de Psicologia. —Brasília: CFP, 2010.

8. Antoniassi, G. J. Nascentes, J.L.B. Sousa, J.P. A esquizofrenia e suas possibilidades de tratamento: uma interface entre reabilitação e clínica. Acta científica. - Vol. 2,n. 2, Patos de Minas, 2010. 